\title{
Leveling of Low Volume and High Mix Production based on a Group Technology Approach
}

\author{
F. Bohnen ${ }^{1}$, J. Deuse ${ }^{1}$ \\ 1 TU Dortmund University, Leonhard-Euler-Straße 5, 44227 Dortmund, \\ Germany
}

\begin{abstract}
Production leveling is an essential element of the Toyota Production System. It aims at balancing production volume as well as production mix to reduce waste, overburden, and unevenness. The application of conventional leveling approaches is limited by the requested product diversity. Because of this production leveling is predominantly used in high volume production. Nevertheless it can be implemented in low volume and high mix production by means of an adapted leveling approach. This approach applies principles of Group Technology for leveling. It uses clustering techniques to group product types into families according to their manufacturing similarity. Based on this, a family-oriented leveling pattern is generated. This paper presents a systematic procedure to level production considering constraints of low volume and high mix production. It describes which grouping criteria can be applied and how product families can be formed for leveling.
\end{abstract}

\section{Keywords:}

Production planning, scheduling, Group Technology

\section{INTRODUCTION}

Production leveling also referred to as production smoothing or heijunka is an essential element of the Toyota Production System and lean production respectively [1]. It aims at balancing production volume as well as production mix and enhancing production efficiency by means of reducing waste, unevenness, and overburden of people or equipment $[1,2]$. When using standard methods, leveling is only implementable in repetitive production environments with limited product diversity, i. e. large scale production [3, 4]. This paper presents an adapted approach that can be used to apply leveling in low volume and high mix production.

This approach is based on the principles and methods of Group Technology. The fundamental idea of Group Technology is to subsume items (e. g. parts, processes, equipment or tools) into families according to their similarity and to take advantage of these groups to increase productivity in manufacturing [5]. In context of the leveling approach presented in this 
paper, Group Technology is utilized to group product types into a manageable number of product families according to their manufacturing similarity. Based on these families production leveling is realized in form of a family-oriented leveling pattern. This pattern is generated by applying a systematic procedure that is adapted from high volume production.

This paper first gives some facts about production leveling in general (section 2). After that it describes a systematic procedure for leveling in low volume and high mix production (section 3 ). In this context the formation of product families (especially the selection of grouping criteria and an adequate grouping algorithm) and the constitution of the leveling pattern are focused on. In section 4 the paper shows how product families are formed for production leveling referring to a real life application. A short summary is given in section 5 .

\section{PRODUCTION LEVELING}

The objective of production leveling is to balance production volume as well as production mix by decoupling production orders and customer demand [1]. In contrast to tayloristic large scale production, leveling distributes production volume and mix to equable short periods [6, 7]. The sequence of these periods describes a periodic manufacturing frequency, i. e. a repetitive pattern. According to this leveling pattern every product type is manufactured within a periodic interval, for example a day or a shift [8]. The so called EPEI-value (every part every interval) depicts the duration of this interval. The general objective is to reduce the EPEI-value to a cost-effective minimum. This leads to maximal flexibility as well as to a balanced work load in production and logistic processes as well $[1,9,10]$.

\subsection{Effects of a Leveled Production}

By decoupling production and customer demand leveling reduces waste, overburden, and unevenness which constitute the three main loss factors for productivity [1]. It avoids variability in the production schedule caused by fluctuation in customer demand. Without leveling this fluctuation leads to waste in form of worker and machine idle times (in case of underutilized capacities) or quality problems, breakdowns, and defects (in case of overburdened capacities) [1]. Leveling enables production to meet the customer demand without holding large volumes of inventory or spare capacities [8]. Concurrently the risk of unsold goods is reduced [1]. Inventories are limited to a controlled standard, the bullwhip-effect is diminished or ideally avoided, and lead times are shortened [11, 12].

Despite these positive effects leveling is not synonymous with a waste-free built-to-order production [11]. By contrast implementing leveling successfully often requires a controlled inventory of finished goods [1]. In this case, a determined degree of waste that is counterbalanced by reducing unevenness and overburdening along the whole value stream is accepted [13]. Furthermore leveling leads to a certain degree of stability in production processes that facilitates implementing other lean production methods like standardized work [9]. Leveling can also be used to specify a target condition that is aimed at in the scope of the continuous improvement process (CIP). Comparing target condition and current situation highlights 
variability that represents an initial point for continuous improvement and sustainable problem solving [11].

\subsection{Requirements for Production Leveling}

To decouple production from customer demand and implement production leveling successfully, a controlled level of inventories is needed [1]. In general leveling goes along with a mixed-model manufacturing in small lots and a high changeover frequency. Because of this minimal setup times for changeover are essential [7]. Additionally leveling requires the utilization of general-purpose machinery and equipment on the one hand [14] and flexible and multi-skilled workers on the other hand $[12,6]$.

The application of conventional leveling (i. e. manufacturing every product type within a periodic interval) is limited to repetitive production environments characterized by constricted product diversity combined with a relative stable and predictable demand $[3,4,10]$. Nevertheless it can be implemented in low volume and high mix production by means of an adapted leveling approach that is presented in the following section.

\section{LEVELING IN LOW VOLUME AND HIGH MIX PRODUCTION}

To implement leveling in low volume and high mix production, an adapted procedure is shown in Figure 1. This procedure is composed of five fundamental steps which are described in the following subsections.

\begin{tabular}{|c|}
\hline analysis \\
\hline constitution of the leveling model \\
\hline formation of part families \\
\hline constitution of the leveling pattern \\
\hline realization \\
\hline
\end{tabular}

Figure 1: Systematic procedure for production leveling in low volume and high mix production.

\subsection{Analysis and Constitution of the Leveling Model}

The systematic procedure starts with a detailed analysis using value stream mapping. Additionally customer demand analysis and Pareto analysis are applied to segment products according to volume, mix, and variation $[13,15]$.

After the analysis, the so called leveling model is constituted. It consists of four elements which have to be concretized to adapt leveling from high volume production to constraints of low volume and high mix production [16]. The leveling model describes the relative amount of production volume that is included in the leveling pattern, e. g. $80 \%$ (first element), and the degree of aggregation, e. g. leveling based on product families or single product types (second element). The third element of the model indicates the time periods for production scheduling, e. g. one day or one 
shift. The fourth element of the model depicts the specific characteristics of leveling, e. g. smoothing production volume only or volume as well as mix. In context of the leveling model planning horizons and units are defined as well. This is described in detail in [16].

\subsection{Formation of Product Families}

To implement leveling in spite of high product diversity, product types are grouped into a manageable number of families according to their manufacturing similarity. Regarding practical application, this represents a task of unsupervised learning because a predisposed number of families and preclassified objects cannot be expected. To perform this kind of learning task, cluster analysis is a commonly used method (cf. e. g. [3]).

\section{Selection of Grouping Criteria}

Product family formation bases on the identification of similarities. These similarities are reflected in different grouping criteria. In general design and manufacturing oriented attributes represent the two categories of grouping criteria which are applicable for product family formation [17]. While design oriented criteria describe products by their geometrical and physical attributes, manufacturing oriented criteria express similarities concerning production sequence and requirements. Last named similarities are required to manufacture products of one family in sequence without or with minimal losses (e. g. caused by changeovers). Because of this manufacturing oriented criteria are chosen to form product families for leveling.

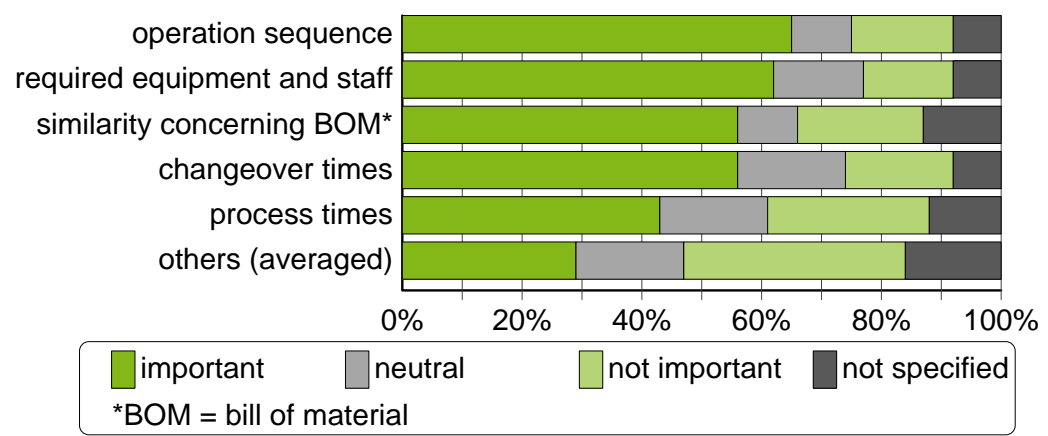

Figure 2: Assessment of criteria to form product families for production leveling. Summarized results of an online survey 106 representatives of different companies participated in.

Adequate grouping criteria to form product families for leveling are operation sequences, required equipment and staff, process times, setup times for changeover, and the share of identical components, parts, or raw material [18]. This hypothesis has been confirmed by means of an empirical evaluation in form of an online survey realized by the Chair of Production System and Industrial Engineering at TU Dortmund University. In sum 106 representatives from companies of different industry sectors participated in the survey. Amongst others they were asked to assess which grouping criteria they choose or rather they would choose to form product families for leveling considering manufacturing similarities. The results are shown 4 
in Figure 2. The selection of grouping criteria essentially depends on the concrete case of application. If two or more criteria are combined for product family formation, [18] and [19] recommend to weight these criteria according to their importance.

Using Cluster Analysis to Form Product Families

Cluster analysis is a commonly used method to form product families. To achieve meaningful clustering results that can be used for leveling, formal criteria and additionally aspects deduced from the case application have to be considered. Formally clustering aims for maximal homogeneity within the groups and maximal heterogeneity between the groups. Regarding usability of the generated families for leveling, aspects like a maximal or minimal number of families, i. e. constraints for the practical application, are important.

Clustering starts with raw data preparation to constitute a standardized data matrix that describes each product by relevant attributes. For this purpose information from bills of material and work schedules are combined. Raw data preparation also includes a check against errors and incomplete data. Subsequent to raw data preparation, a proximity measure is chosen to quantify the similarity, or rather the dissimilarity, of the objects in the raw data matrix. Which proximity measure is selected, depends on the considered data structure, especially the scales of measurement. An overview of different proximity measures is e. g. given in [20].

In the next step clustering is executed by mathematical algorithms. [20] for example presents an overview of commonly used clustering algorithms. Which algorithm delivers the best results highly depends on the case of application, i. e. the given data. Because of this, a range of different algorithms has to be applied and evaluated in the next step. This also includes the choice of an optimal partition size, i. e. the optimal number of product families.

\subsection{Constitution and Realization of the Leveling Pattern}

The leveling pattern is conventionally characterized by the manufacturing interval reflected in the EPEI-value, a determined order sequence (i. e. the manufacturing intervals are arranged in a fixed sequence), and production volumes for each interval. In a leveling pattern based on product families, every family is manufactured within a repetitive period (see Figure 3 ). In contrast to conventional leveling based on product types, the periodic manufacturing interval is quantified by the EFEI-value (every family every interval).

To constitute the leveling pattern, product families are segmented into runners and strangers. Runner families are characterized by high volume, high order frequency, and low variation in demand [cf. 21]. In contrast strangers are produced in relatively low volume, low order frequency, and high variation in demand [cf. 2]. Based on the initial analysis runners and strangers within the families are identified. The leveling pattern includes constant manufacturing periods for each runner family. Stranger families are considered summarized, for example in form of one or more periods in the pattern. 


\begin{tabular}{|c|c|c|c|}
\hline \multirow{3}{*}{$\begin{array}{c}\text { production } \\
\text { interval } \\
(\mathrm{EFEI}= \\
3 \text { days })\end{array}$} & \multirow{3}{*}{$\begin{array}{l}\text { Monday } \\
\text { Tuesday } \\
\text { Wednesday }\end{array}$} & product family $A$ & product family $B$ \\
\hline & & product family C & product family D \\
\hline & & product family $\mathrm{E}$ & strangers \\
\hline & \multirow{2}{*}{$\begin{array}{c}\text { Thursday } \\
\text { Friday }\end{array}$} & product family $A$ & product family B \\
\hline & & product family C & product family $D$ \\
\hline
\end{tabular}

Figure 3: Schematic leveling pattern based on product families.

According to demand forecasts the length of the manufacturing periods in the leveling pattern, i.e. time or capacity slots, are determined for runner and stranger families and the EFEl-value is defined. The EFEI-value essentially depends on the available overall capacity for changeover, inventories of finished goods, overall lead and delivery times. The sequence of the periods in the leveling pattern is constituted by means of a familyoriented setup matrix. Thus, changeover times between the families are minimized. The leveling pattern is determined for a defined time period (the so called leveling period). In case of changes in product mix and/or customer demand the leveling pattern has to be adapted cyclically. More details on the constitution of the leveling pattern are given in [15] and [16].

Finally leveling is realized by scheduling production orders into the leveling pattern. In the course of realization, deviation between the planed pattern, i. e. the target condition, and the current condition becomes obvious. This deviation represents starting points for the CIP.

\section{REAL LIFE APPLICATION}

In a company of engineering industry the abovementioned procedure was applied to level a production area with characteristic attributes of low volume and high mix production. Product families were formed according to the share of identical machine equipment and raw material. Thus changeover times within the families were expected to be minimal. Euclidean distance was chosen as proximity measure. A combination of standard clustering algorithms delivered adequate clustering results. For cluster validation a so called desirability index was used. This index combines formal criteria and criteria derived from the case of application [cf. 21]. Regarding formal and real life related criteria a partition size of 24 families was determined.

Figure 4 shows the results of a family-oriented analysis on forecasted production volume. According to the analysis 6 families represent $85 \%$ of the forecasted production volume and a rate of $29 \%$ of the considered production types. In sum the remaining 18 families account for $15 \%$ of the production volume and $71 \%$ of the product types. 
$43^{\text {rd }}$ CIRP Conference on Manufacturing Systems

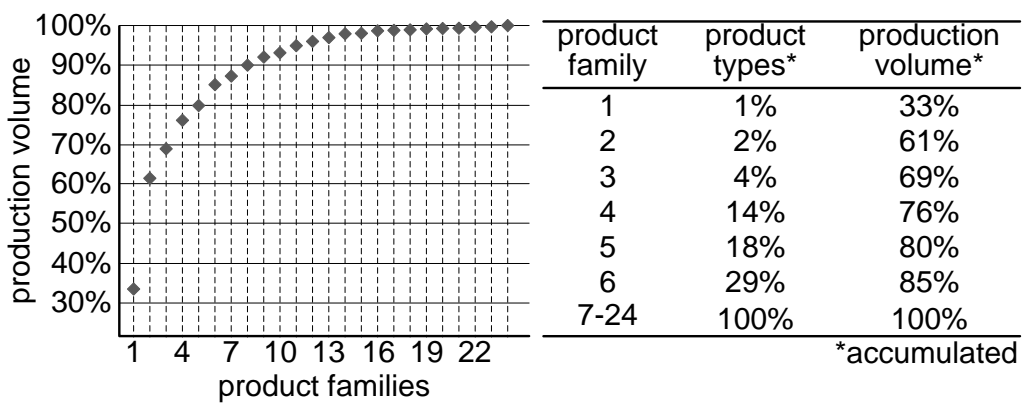

Figure 4: Family-oriented Pareto analysis on production volume.

The formed product families enable the constitution of family-oriented leveling pattern. In this context the 6 families representing $85 \%$ of the production volume can be classified as runner families. Correspondingly the rest of the basic population is treated as strangers. Based on this segmentation, the EFEI-value has to be defined considering lead and delivery times, inventories, and available capacities for changeover. To fix the sequence of the families in the leveling pattern a family-oriented setup matrix is utilized.

\section{SUMMARY}

This paper presents a systematic procedure for leveling of low volume and high mix production based on the principles of Group Technology. This procedure is adapted from the conventional leveling approach applied in high volume production. It uses clustering techniques to subsume the large number of product types into a manageable number of product families. These families are utilized to constitute a family-oriented leveling pattern. Focusing on the clustering process this paper describes which grouping criteria can be chosen and how product families can be formed for leveling. In this context a real life application is quoted. Additionally, the paper briefly describes how the family oriented leveling pattern can be constituted.

\section{ACKNOWLEDGMENTS}

This paper presents results of a research project (AiF-No. 15865N/1) funded by the German Federal Ministry of Economics and Technology (BMWi) via the German Federation of Industrial Research Associations 'Otto von Guericke' (AIF) by order of the GVB e. V.. We would like to record our appreciation of this promotion and support.

\section{REFERENCES}

[1] Liker, J.K., 2004, The Toyota Way, McGraw-Hill, New York.

[2] Dennis, P., 2007, Lean production simplified, 2nd ed., Productivity Press, New York. 
[3] Deuse, J., Birkmann, S., Harms, T., 2007, Einsatz der Gruppentechnologie zur Nivellierung in der variantenreichen Kleinserie, Industrie Management 23: 45-48.

[4] Slomp, J., Bokhorst, J.A.C., Germs, R., 2009, A Lean Production Control System for High-Variety/Low-Volume Environments, Production Planing \& Control 20: 586-595.

[5] Shunk, D.L., 1985, Group Technology Provides Organized Approach to Realizing Benefits of CIMS, Industrial Engineering 17: 74-80.

[6] Zäh, M.F., Aull, F., 2006, Lean Production-Methoden und Interdependenzen, wt Online 96: 683-687.

[7] Syska, A., 2006, Produktionsmanagement, Gabler, Wiesbaden.

[8] Matzka, J., Di Mascolo, M., Furmans, K., 2009, Buffer Sizing of a Heijunka Kanban System, J. Intell. Manuf., Online First, 09/2009.

[9] Schürle, P., 2009, Produktionsnivellierung, In: Dickmann, P. (ed.): Schlanker Materialfluss, 2nd ed., Berlin, Springer: 248-254.

[10] Hüttmeir, A., de Treville, S., van Ackere, A., Monnier, L., Prenninger, J., 2009, Trading off between Heijunka and Just-In-Sequence, Int. J. Product. Econ. 118: 501-507.

[11] Rother, M., 2009, Die Kata des Weltmarktführers, Campus, Frankfurt/Main.

[12] Coleman, J.B., Vaghefi, M.R., 1994, Heijunka, Prod. Inventory Manag. J. 35: 31-35.

[13] Smalley, A., 2005, Produktionssysteme glätten, Lean Management Institute, Aachen.

[14] Ohno, T., 1993, Das Toyota-Produktionssystem, Campus, Frankfurt/ Main.

[15] Wuthnow, A.; Deuse, J., 2009, Systematische Nivellierung von Wertströmen, ZWF 104: 229-234.

[16] Buhl, M., Bohnen, F., Deuse, J., Schneider, R., 2009, Effiziente Kleinserienfertigung durch Produktionsnivellierung, Productivity Management 14: 19-22.

[17] Lee-Post, A., 2000, Part Family Identification Using a Simple Genetic Algorithm, Int. J. Prod. Res. 38: 793-810.

[18] Birkmann, S., Deuse, J., 2007, Using a Group Technology Approach to Level a Low Volume and High Mix Production, $12^{\text {th }}$ Annual International Conference on Industrial Engineering, Proceedings: 265-270.

[19] Lee, S.D., Chen, Y.L., 1997, A Weighted Approach for Cellular anufacturing Design, Int. J. Prod. Res. 35: 1125-1146.

[20] Backhaus, K., Erichson, B., Plinke, W., Weiber, R., 2006, Multivariate Analysemethoden, 11th ed., Springer, Berlin.

[21] Weihs, C., Szepannek, G., 2009, Distances in Classification, ICDM 2009, LNAI 5633: 1-12. 